\title{
La implantación y el seguimiento de la Ventanilla Única en la Comunidad Autónoma de Madrid
}

Gema Pastor Albaladejo* y M. José García Solana*

Palabras clave: Ventanilla Única, modernización administrativa, atención al ciudadano, eficiencia, herramientas de gestión pública, accesibilidad, cooperación administrativa, intercomunicación de registros, simplificación de procedimientos.

\section{Ventanilla única y modernización}

El Proyecto Ventanilla Única surge en España en 1996 coincidiendo con la segunda ola de reformas de las Administraciones públicas ${ }^{1}$ y dentro del marco teórico de la Nueva Gestión Pública.

En este contexto el Proyecto pretende incorporar criterios de eficacia y eficiencia administrativa al introducir en los procedimientos principios de racionalización y simplificación que posibiliten la creación de estructuras administrativas flexibles y orientadas a la dirección por objetivos, la mejora continua y sistemas de evaluación y seguimiento de la gestión. La eficiencia administrativa que aquí se postula busca introducir cambios organizativos al considerar que «existe una relación de eficacia entre las estructuras y los resultados que obtiene la organización» (Wright 1997: 29).

Para la consecución de estos objetivos la Ventanilla Única incorpora un conjunto de actuaciones entre las que destacamos las siguientes:

a) El rediseño de las estructuras organizativas. Esta actuación supone la creación de una red de puntos de atención al ciudadano y unidades de registro de documentación que implican la eliminación de un cierto número de unida-

* Profesora de Ciencia Politica y de la Administración de la Universidad Complutense de Madrid.

** Agente de Empleo y Desarrollo Local del Ayuntamiento de Velilla de San Antonio.

1 «Una ola más radical, ya en los noventa, que enfatiza el mercado y el papel del gerente como un hacedor de políticas. Se utilizan términos como flexibilidad, responsabilidad, reingeniería, apoderamiento, optimismo e igualitarismo» (Olías de Lima 2001: 21). 
des internas y consecuentemente la descentralización de la atención al ciudadano dando lugar a organizaciones aplanadas.

El modelo Ventanilla Única implica crear en el ámbito territorial y competencial de otra Administración (la Administración Local) una unidad de línea a la que se dirigen los escritos y comunicaciones que son responsabilidad en su tramitación y resolución de una Administración diferente a la que los recepciona.

Por tanto, representa una novedosa fórmula de división de trabajo interadministrativo que quiere dar respuesta tanto a objetivos y condiciones cambiantes del entorno como a necesidades ${ }^{2}$ dispersas y alejadas. Una racionalización de la actuación administrativa que busca eliminar duplicidades innecesarias y rentabilizar la red de organizaciones públicas.

Para ello, las unidades de registro y atención deberán asumir características similares y compartir criterios comunes de eficiencia administrativa (accesibilidad, tiempos de atención, tiempos de respuesta) que son básicos para el éxito del Proyecto.

Ello supone mejorar el funcionamiento interno de la Administración al conjugar «utilidad social», al reducir los costes externos soportados por los ciudadanos, y «rentabilidad administrativa», al mejorar los tiempos de respuesta de la organización.

b) El rediseño de los procedimientos. Este concepto hace referencia tanto a la simplificación en los procedimientos, a la reducción de trámites y documentación, como a la normalización de documentos a través de un lenguaje común y cercano al ciudadano.

Hasta la fecha en el ámbito de la Administración Local se han normalizado básicamente indicadores de registro ${ }^{3}$. No ocurre lo mismo en algunas Administraciones Regionales, entre ellas la Comunidad Autónoma de Madrid, ya que desde el año 2001 en su Proyecto de Ventanilla de Tramitación Administrativa lo que se pretende es racionalizar y simplificar los procedimientos administrativos.

c) La incorporación del enfoque hacia el ciudadano. Esta actuación representa la principal aportación de la Ventanilla Única como herramienta de gestión, incardinada en el marco de la Nueva Gestión Pública, lo que marcaría la diferencia respecto a anteriores reformas limitadas al ámbito intraorganizativo. La incorporación de este enfoque trata de configurar una Administración que responda a los «requerimientos de modernización de nuestra sociedad» (Acuerdo de 23 de febrero de 1996). Para ello, es necesario introducir en el marco legal-formal que regula las relaciones entre Administración y sociedad mecanismos de comunicación que rompan la autarquía del modelo burocrático acercando al beneficiario final la acción pública de la Administración. «La creación de herramientas al servicio de la generación externa de información implica la apertura de la organización al ciudadano, de la participación indirecta de éste en la definición de sus objetivos y sus politicas. (Pastor Albaladejo 2001: 284).

\footnotetext{
${ }^{2}$ Presentar solicitudes, escritos y comunicaciones es la necesidad común a resolver mediante la creación de un sistema intercomunicado de registros que relacionen los registros de las diferentes Administraciones Públicas.

3 "Indicación en sus asientos de su numero, epígrafe expresivo de su naturaleza, fecha de entrada, la fecha y bora de su presentación, interesado u órgano administrativo remitente, persona u órgano administrativo al que se dirige, así como una referencia al contenido del escrito o comunicación que se registra» (Acuerdo de 23 de febrero de 1996, del Consejo de Ministros, para la formalización con las Entidades que integran la Administración Local de los convenios previstos en el artículo 38.4 b), de la Ley 30/1992, del Régimen Jurídico de las Administraciones Públicas y del Procedimiento Administrativo Común).
} 
En este contexto la Ventanilla Única permite una mayor accesibilidad de la Administración al potenciar desde las Entidades Locales la inmediatez con su entorno, dando lugar a una Administración receptora y aperturista a las peticiones de los ciudadanos. «Ello supone que el ciudadano participa y se implica en la gestión pública principalmente de varias maneras; solicitando información, presentando solicitudes, reclamaciones y sugerencias, lo que permite introducir la percepción de los ciudadanos en la prestación del servicios; y exigiendo no sólo la prestación de los servicios sino un nivel de calidad en los mismos» (Pastor Albadalejo y García Solana 2005: 65).

Además, el Proyecto Ventanilla Única introduce una visión heterogénea del ciudadano (usuario final), frente a la imagen homogénea del administrado, ya que éste solicita niveles y contenidos de información diferenciada. Esta circunstancia ha permitido la creación de nuevos canales de comunicación entre la Administración y los ciudadanos acercando servicios administrativos a través de medios como la teleadministración (pago de tasas, modelos de impresos, licitación pública) caracterizados por la multiaccesibilidad.

d) La interconexión entre Administraciones. Junto al aperturismo de la Administración Pública a los ciudadanos, debemos señalar que la Ventanilla Única refuerza los mecanismos de cooperación administrativa. Introduce un sistema intercomunicado de registros, bases y documentación que aportan una visión comprensible y abarcable de una realidad social y territorial dispersa ${ }^{4}$.

Esta herramienta postula la creación de una Administración Única que suprima duplicidades y solapamientos entre Administraciones al margen del ámbito competencial que les corresponde. Si bien, esta actuación deja abierta dos cuestiones: por un lado, la relacionada con el nivel de reparto de responsabilidades entre Administraciones Públicas participantes en el Proyecto; y por otro lado, la autonomía de cada nivel de Administración.

\section{La ventanilla única en la Comunidad Autónoma de Madrid}

En el ámbito de geográfico de la Comunidad de Madrid, la definición de Ventanilla Única se caracteriza por una complejidad respecto al contenido que se le da a este concepto, ya que con él se hace referencia a tres líneas de actuación cronológicamente diferenciadas: La primera se relaciona con la Ventanilla Única Empresarial; la segunda con el modelo de Ventanilla Única implantado en las Entidades Locales fruto de la adhesión de los municipios de la Comunidad Autónoma de Madrid al Convenio Marco; y un tercer tipo referido a la Ventanilla Única desarrollada en la Comunidad de Madrid a partir de la puesta en marcha de los Planes de Simplificación Administrativa.

\subsection{Los primeros pasos en la implantación de la Ventanilla Única en la Comunidad Autónoma de Madrid: la Ventanilla Única Empresarial}

Los primeros pasos en la implantación de la Ventanilla Única en el espacio geográfico de la Comunidad de Madrid surgen en el año 1995, fecha en la que se puso en marcha el Proyecto de Ventanilla Única Empresarial.

\footnotetext{
${ }^{4}$ «Ventanilla Única como un conjunto de medidas e instrumentos de colaboración interadministrativa que permitan un proceso coordinado de implantación de un sistema intercomunicado de los registros administrativos, el intercambio de las bases de datos e instrumentos de información y atención al ciudadano de las respectivas Administraciones y la simplificación e integración de los trámites y procedimientos administrativos en que participen las administraciones intervinientes». (Maíz Carro, L. Directora General de Organización Administrativa. MAP).
} 
El objetivo principal de esta herramienta era el tratar de reducir los plazos de los procedimientos administrativos que debían seguirse por las personas interesadas en constituir o ampliar una empresa o centro de trabajo, con la finalidad de fomentar la creación de empleo.

Los actores implicados en el desarrollo de este Proyecto fueron: la Dirección General de Calidad de los Servicios (quien ejerció la coordinación); todas aquellas Direcciones Generales o Unidades con atribuciones en materia de empleo o en aspectos relacionados con la creación de empresas; el Organismo Autónomo de Informática y Comunicaciones de la Comunidad de Madrid (que prestó el apoyo tecnológico necesario para la implantación del Proyecto); y dos consultorías Coopers \& Lybrand y KPMG (quienes diseñaron la metodología para su puesta en práctica). Además debemos destacar que desde su inicio, este Proyecto también fue impulsado por las Asociaciones representativas de los empresarios madrileños (CEIM y Jóvenes Empresarios).

La implantación de la Ventanilla Única Empresarial en la Comunidad de Madrid supone una primera aproximación a un Proyecto mucho más amplio cuya filosofía de fondo es la aproximación de la Administración a los ciudadanos. Y en este sentido, unos años después se firmará un Convenio Marco entre la Administración General del Estado y la Administración de la Comunidad de Madrid cuyo objetivo será la implantación de la Ventanilla Única en aquellos municipios de la Administración Regional que así lo solicitasen.

\subsection{La Ventanilla Única en las entidades locales de la Comunidad de Madrid}

En la Comunidad Autónoma de Madrid la búsqueda de una mayor accesibilidad de la Administración Pública con el ciudadano traerá a colación la firma en 1997 de un Convenio Marco entre la Administración General del Estado, la Administración regional y las Entidades Locales para la implantación de un sistema intercomunicado de registros ${ }^{5}$.

Este Convenio Marco viene a impulsar la implantación de la Ventanilla Única en el ámbito geográfico de la Comunidad de Madrid ya que pretende conseguir una mayor participación de las Entidades Locales en la prestación de servicios a los ciudadanos, en el sentido de facilitar la información que demanden sobre cualquier servicio público con independencia de la Administración titular del servicio y de la pertenencia territorial del centro u oficina de atención al que acudan.

En esta línea, en el Cuadro 1 se muestra claramente la evolución que ha tenido el Proyecto Ventanilla Única en los dos modelos generales de Convenio (Convenio Bilateral y Convenio Marco) y, en concreto, en el texto del Convenio Marco para la Comunidad de Madrid. En él no sólo se pretende una intercomunicación de registros sino establecer pautas normalizadas de comunicación e información.

\footnotetext{
${ }^{5}$ No debemos olvidar que a pesar de que en 1996 existía un Convenio Bilateral que permitía la adhesión de las entidades locales al Proyecto Ventanilla Única no será hasta 1997 cuando este Proyecto recobre un mayor protagonismo al incorporarse en él, y mediante la firma de un Convenio Marco, a las Comunidades Autónomas.
} 


\section{CUADRO 1 \\ Comparativa Convenios ventanilla única}

\begin{tabular}{|c|c|c|c|}
\hline & $\begin{array}{c}\text { Convenio Bilateral } \\
1996\end{array}$ & $\begin{array}{c}\text { Convenio Marco } \\
1997\end{array}$ & $\begin{array}{c}\text { Convenio Marco CAM } \\
1997\end{array}$ \\
\hline Objetivos & $\begin{array}{l}\text { 1. Presentar en los } \\
\text { registros solicitudes, } \\
\text { escritos y } \\
\text { comunicaciones. } \\
\text { 2. Dejar constancia en los } \\
\text { registros de la entrada de } \\
\text { los documentos. } \\
\text { 3. Remisión de } \\
\text { documentos registrados. }\end{array}$ & $\begin{array}{l}\text { 1. Determinación de } \\
\text { medidas e instrumentos de } \\
\text { colaboración que permitan } \\
\text { un proceso coordinado de } \\
\text { implantación de un sistema } \\
\text { intercomunicado de } \\
\text { registros administrativos. } \\
\text { 2. Intercambio de las bases } \\
\text { de datos e instrumentos de } \\
\text { información y atención al } \\
\text { ciudadano de las respectivas } \\
\text { Administraciones } \\
\text { 3. Simplificación e } \\
\text { integración de los trámites y } \\
\text { procedimientos } \\
\text { administrativos en que } \\
\text { participen las } \\
\text { Administraciones } \\
\text { intervinientes. }\end{array}$ & $\begin{array}{l}\text { 1. Aplicación de criterios } \\
\text { comunes en el } \\
\text { funcionamiento de los } \\
\text { Registros. } \\
\text { 2. Coordinación e } \\
\text { interconexión informática de } \\
\text { registros. } \\
\text { 3. Información al ciudadano. } \\
\text { 4. Simplificación de trámites } \\
\text { y procedimientos. }\end{array}$ \\
\hline
\end{tabular}

Fuente: Elaboración propia.

Teniendo en cuenta el telón de fondo descrito y entrando al detalle, el Convenio firmado por la Comunidad de Madrid y la Administración General del Estado tiene como objetivo principal la determinación de medidas e instrumentos de colaboración que permitan: a) un proceso coordinado de implantación de un sistema intercomunicado de los registros administrativos; b) el intercambio de bases de datos e instrumentos de información y atención al ciudadano de las Administraciones adscritas al Convenio; c) y la simplificación e integración de los trámites y procedimientos administrativos en que participen las Administraciones intervinientes. Para el cumplimiento de los objetivos descritos se establecen una serie de compromisos entre las Administraciones participantes (Cuadro 2).

En la actualidad, nos encontramos con que en el seno de la Comunidad de Madrid existen alrededor de unas 169 Entidades Locales que se han adherido al Convenio Marco y que en consecuencia han puesto en práctica el modelo Ventanilla Única. Sin embargo, pocos son los datos de los que disponemos para saber cuál ha sido el nivel de implantación de este Proyecto y el grado de cumplimiento de los compromisos adquiridos por las Administraciones participantes. 


\section{CUADRO 2 \\ Compromisos del Convenio Marco entre la Administración General del Estado y la Comunidad de Madrid}

\begin{tabular}{|c|c|}
\hline $\begin{array}{c}\text { Nivel } \\
\text { Administrativo }\end{array}$ & Línea de Actuación \\
\hline EELL & $\begin{array}{l}\text { - Admitir en sus registros solicitudes, escritos o comunicaciones } \\
\text { dirigidas a los órganos de la AGE y de la Administración de la } \\
\text { Comunidad de Madrid o a las Entidades de Derecho Público } \\
\text { vinculadas o dependientes de aquéllas, con independencia de su } \\
\text { localización territorial. } \\
\text { - Dejar constancia en sus Registros de la entrada la documentación } \\
\text { - Rertinente. }\end{array}$ \\
\hline AGE/CCAA & $\begin{array}{l}\text { - Proporcionar información y actualizarla periódicamente sobre: los } \\
\text { organos que integran sus respectivas organizaciones, sus Entidades } \\
\text { vinculadas o dependientes a las Entidades locales que se adhieren al } \\
\text { Convenio. } \\
\text { - Facilitar instrumentos de información al ciudadano sobre las } \\
\text { funciones y actividades de los órganos de sus respectivas } \\
\text { Administraciones y de sus Entidades vinculadas o dependientes a las } \\
\text { Entidades locales que se adhieren al Convenio. } \\
\text { - Prestar asistencia técnica y colaboración sobre organización o } \\
\text { informatización de los Registros a las Entidades Locales que se } \\
\text { adhieran al Convenio. }\end{array}$ \\
\hline $\begin{array}{c}\text { AGE/ CCAA/ } \\
\text { EELL }\end{array}$ & $\begin{array}{l}\text { - Comunicar cualquier medida de informatización de sus Registros } \\
\text { que puede afectar a la compatibilidad de los sistemas de } \\
\text { intercomunicación, y negociar y formalizar el correspondiente } \\
\text { Convenio de colaboración que garantice la compatibilidad } \\
\text { informática y la coordinación de dichos registros. } \\
\text { - Promover intercambios de información sobre sus respectivas } \\
\text { organizaciones y competencias, así como las funciones, prestaciones } \\
\text { y servicios al ciudadano. Este intercambio debe ir acompañado de } \\
\text { una accesibilidad por parte de cualquiera de las Administraciones } \\
\text { intervinientes a dicha información y a los instrumentos que utilizan. } \\
\text { - Determinar los trámites y procedimientos susceptibles de } \\
\text { simplificación y/o integración }\end{array}$ \\
\hline
\end{tabular}

Fuente: Elaboración propia

\subsection{La Ventanilla Única en la Administración Regional. Avanzando hacia la Ventanilla de Tramitación Administrativa.}

La implantación de la Ventanilla Única en las Entidades Locales de la Comunidad de Madrid va a coincidir en el tiempo con la aprobación del Decálogo de Derechos de los Ciudadanos y la creación de la Dirección General de Calidad de los Servicios ${ }^{6}$. Este conjunto de medidas desarrolladas por la Administración Regional van a marcar el inicio de una política de modernización, mejora y calidad en la prestación de los servicios a los ciudadanos que desembocará a partir del año 2001 en la formulación de los Planes de Simplificación Administrativa.

${ }^{6}$ Véase el Decreto 84/1995. 
Como podemos apreciar en el Cuadro 3, a pesar de que el Convenio Marco que da lugar a la implantación del modelo Ventanilla Unica en el seno de la Comunidad de Madrid se firma unos años antes de la aprobación del primer Plan de Simplificación Administrativa, los objetivos propuestos en el citado Proyecto se recogerán y serán desarrollados con posterioridad en los dos Planes de Simplificación Administrativa (PESG).

\section{CUADRO 3 \\ Comparativa de los planes de simplificación y objetivos del proyecto de ventanilla única dentro de los planes}

\begin{tabular}{|c|c|c|c|}
\hline & $\begin{array}{l}\text { Proyecto Ventanilla } \\
\text { Única }\end{array}$ & $\begin{array}{l}\text { 1. PESG } \\
(2001-2003)\end{array}$ & $\begin{array}{l}2 .^{\circ} \text { PESG } \\
(2005-2007)\end{array}$ \\
\hline $\begin{array}{l}\text { Objetivo } \\
\text { General }\end{array}$ & $\begin{array}{l}\text { Mejorar calidad del servicio } \\
\text { al ciudadano }\end{array}$ & $\begin{array}{l}\text { Mejorar calidad del servicio al } \\
\text { ciudadano }\end{array}$ & $\begin{array}{l}\text { Mejorar calidad del servicio al } \\
\text { ciudadano }\end{array}$ \\
\hline Objetivos & $\begin{array}{l}\text { 1. Mejora de los canales de } \\
\text { comunicación } \\
\text { interadministrativa. } \\
\text { 2. Incorporación de un } \\
\text { sistema de comunicaciones } \\
\text { avanzadas entre } \\
\text { Administraciones y } \\
\text { ciudadanos y empresas }\end{array}$ & $\begin{array}{l}\text { 1. Simplificar y mejorar el } \\
\text { Sistema de Información al } \\
\text { ciudadano. } \\
\text { 2. Simplificar y facilitar las } \\
\text { relaciones entrelos ciudadanos y } \\
\text { la Administración de la CAM } \\
\text { 3. Simplificar y racionalizar los } \\
\text { procedimientos administrativos. } \\
\text { 4. Simplificar y facilitar la } \\
\text { tramitación interna de los } \\
\text { expedientes. } \\
\text { 5. Simplificación y mejora } \\
\text { continua de la gestión } \\
\text { administrativa para la tona de } \\
\text { decisiones (políticas y } \\
\text { responsables de la gestión), } \\
\text { mediante la utilización de las } \\
\text { técnicas y sistemas de } \\
\text { información necesarios. }\end{array}$ & $\begin{array}{l}\text { 1. Mejorar y facilitar las } \\
\text { relaciones entre los } \\
\text { ciudadanos y la } \\
\text { Administración. } \\
\text { 2. Simplificar la tramitación } \\
\text { administrativa. } \\
\text { 3. Mejorar la organización y el } \\
\text { trabajo de los empleados } \\
\text { públicos haciendo uso de la } \\
\text { formación como una } \\
\text { herramienta de cambio } \\
\text { 4. Implicar a toda la } \\
\text { organización para } \\
\text { conseguir una } \\
\text { Administración más } \\
\text { moderna y racional. } \\
\text { 5. Extender y generalizar las } \\
\text { nuevas tecnologáas. } \\
\text { 6. Alcanzar un mayor grado } \\
\text { de eficiencia en el } \\
\text { funcionamiento de la } \\
\text { Administración } \\
\text { autonómica. }\end{array}$ \\
\hline Acciones & $\begin{array}{l}\text { - Interconexión de } \\
\text { registros entre las tres } \\
\text { Administraciones } \\
\text { públicas } \\
\text { - Servicio de } \\
\text { información } \\
\text { administrativa y } \\
\text { tramitación electrónica } \\
\text { de expedientes } \\
\text { administrativos. }\end{array}$ & $\begin{array}{l}\text { Extra-organizativa } \\
\text { - Sistema de información al } \\
\text { ciudadano } \\
\text { - Administración electrónica } \\
\text { Intra-organizativa } \\
\text { - Simplificación y } \\
\text { racionalizacion de los } \\
\text { procedimientos } \\
\text { administrativos } \\
\text { - Gestión informatizada de } \\
\text { expedientes } \\
\text { - Sistema de indicadores de } \\
\text { gestión }\end{array}$ & $\begin{array}{l}\text { - Servicios comunes en } \\
\text { tramitación electrónica. } \\
\text { - Servicios de respuesta } \\
\text { inmediata } \\
\text { - Municip@ } \\
\text { - La comunidad en tu } \\
\text { - móvil } \\
\text { - Papel cero } \\
\text { - Licitación electrónica } \\
\text { - Cita previa } \\
\text { - Portal del empleado } 1\end{array}$ \\
\hline
\end{tabular}


Durante el Primer Plan de Simplificación Administrativa 2001-2003 la Ventanilla Única implantada en las Entidades Locales se desarrolla en dos subproyectos considerados a largo plazo y en los que la mayor parte de las acciones prevista ya se incluían en el Convenio Marco.

El primer subproyecto estaba destinado a la interconexión de registros. Los principales fines eran: el alcanzar la intercomunicación de la totalidad de unidades registrales localizadas en los tres niveles de Administración Pública; y la interconexión telemática de todos los registros de entrada y salida. Por este motivo el principal objetivo de la Comunidad de Madrid fue la búsqueda del mayor número de adhesiones de Entidades Locales al Convenio Marco firmado entre Administración General del Estado y la Administración Regional.

La segunda fase o subproyecto iba dirigido a ofrecer información general sobre los procedimientos administrativos y a iniciar y tramitar expedientes de forma telemática. En este sentido, y a pesar de la novedad con la que se plantea la Ventanilla Única, cabe señalar la existencia de experiencias similares sobre intercambio de información que ya habían sido desarrolladas entre la Comunidad de Madrid y las Entidades Locales. En concreto, el Proyecto GEMA abordaba dos líneas de trabajo coincidentes con la Ventanilla Única: por un lado, impulsar la comunicación; y por otro, el acceso directo de los ciudadanos a la información ofrecida por los municipios.

El Segundo Plan de Simplificación Administrativa 2005-2007 comienza considerando a la Ventanilla Única como un Proyecto cerrado y finalizado. Sorprende tal hecho teniendo en cuenta que, como se verá posteriormente en el apartado tercero, únicamente se ha desarrollado Ventanilla Única en su faceta de registro de entrada de documentos y de intercambio básico de información, sin abordar el resto de los apartados incluidos en el Convenio Marco de la Comunidad de Madrid (véase Cuadro 1) y mucho menos los propuestos en el segundo subproyecto del primer Plan de Simplificación Administrativa.

A pesar de esta ruptura en la evolución del Proyecto Ventanilla Única cabría vislumbrar cierta continuidad con el Proyecto Municip@ en lo que respecta a la implantación de la Administración electrónica e interconexión de registros, bases, etcétera. Dicho Proyecto se completa con dos actuaciones dentro del Segundo Plan de Simplificación. Estas dos líneas de actuación son: a) los servicios de respuesta inmediata - entendiendo por ellos el conjunto de acciones destinadas a modernizar y racionalizar procedimientos administrativos cercanos al ciudadano, agilizar y facilitar la relación de los ciudadanos con la Administración y simplificar tramitación administrativa, entre otros -; b) y los servicios comunes de tramitación electrónica - referidos a la reducción de tiempos, mayor claridad en el diálogo con los ciudadanos y reducción de documentación a presentar.

El Cuadro 4 recoge los tres proyectos de comunicación e intercambio de información desarrollados hasta la fecha en las Entidades Locales de la Comunidad de Madrid. Y en los que partiendo de los objetivos perseguidos por cada uno de ellos podemos establecer cierta línea de continuidad y coincidencia, a pesar de que no se encuentre recogido expresamente en los Planes de Simplificación Administrativa de la Comunidad de Madrid.

${ }^{7}$ Véase la $2^{a}$ Fase del Plan Estratégico de Simplificación de la Gestión Administrativa 2005-2007. Madrid: Consejería de Presidencia, Dirección General de la Calidad de los Servicios y Atención al Ciudadano, 2005. 


\section{CUADRO 4.}

Cuadro comparativo de los proyectos de intercomunicación administrativa para EELL

\begin{tabular}{|c|c|c|c|}
\hline & Proyecto GEMA & $\begin{array}{l}\text { Proyecto Ventanilla Única } \\
\text { (Convenio en la CAM) }\end{array}$ & Proyecto Municip@ \\
\hline Objetivos & $\begin{array}{l}\text { 1. Impulsar la } \\
\text { comunicación. } \\
\text { 2. Acceso directo de los } \\
\text { ciudadanos a la } \\
\text { información ofrecida por } \\
\text { los municipios. }\end{array}$ & $\begin{array}{l}\text { 1. Aplicación de criterios } \\
\text { comunes en el } \\
\text { funcionamiento de los } \\
\text { Registros. } \\
\text { 2. Coordinación e } \\
\text { interconexión informática } \\
\text { de registros. } \\
\text { 3. Información al ciudadano } \\
\text { 4. Simplificación de trámites y } \\
\text { procedimientos. }\end{array}$ & $\begin{array}{l}\text { 1. Ofrecer y dotara la } \\
\text { Administración Local de } \\
\text { la región de mecanismos } \\
\text { fiables de información y } \\
\text { servicios que pueda ser } \\
\text { ofrecidos a los } \\
\text { ciudadanos. } \\
\text { 2. Simplificar la tramitación } \\
\text { inter-administración. }\end{array}$ \\
\hline
\end{tabular}

Fuente: Elaboración propia.

\section{El seguimiento de la Ventanilla Única en los municipios de la Comunidad Autónoma Madrid}

Podemos establecer dos periodos diferenciados en el seguimiento de la Ventanilla Única en la Comunidad de Madrid:

a) El primer periodo dura aproximadamente dos años (1998-1999) y se caracteriza por ser la etapa en que se constituye el órgano formal previsto en el Convenio Marco ${ }^{8}$ de Ventanilla Unica firmado por la Administración General del Estado y la Comunidad de Madrid. Este órgano denominado Comisión de Seguimiento y Evaluación debía asumir (según el citado marco normativo) las funciones derivadas de la evaluación y el seguimiento de las entidades locales del ámbito geográfico de la Comunidad de Madrid que solicitasen suscribirse al Convenio Marco e implantasen la Ventanilla Única.

b) A partir del año 1999 comienza un segundo periodo (que podemos denominar informal) en la evaluación y el seguimiento de la Ventanilla Única en la Comunidad de Madrid. En esta etapa nos encontramos con que desaparece el órgano que formalmente tenía asignadas las funciones en el seguimiento y la evaluación de este Proyecto, por lo que estas actividades son asumidas a partir de entonces por la Oficina de Atención al Ciudadano de la Comunidad de Madrid.

A continuación, analizaremos cuál ha sido el contenido real de las dos etapas a las que hemos hecho referencia. Para ello, comenzaremos dentro del periodo de seguimiento formal por un estudio del órgano que tiene

${ }^{8}$ Véase cláusula decimocuarta del Convenio Marco del 21 de mayo de 1997 firmado por la Administración General del Estado y la Comunidad Autónoma de Madrid para la colaboración en la progresiva implantación de un sistema intercomunicado de registros entre la Administración General del Estado, la Administración de la Comunidad de Madrid y las Entidades Locales del ámbito territorial de dicha Comunidad Autónoma. 
asignadas las funciones en la realización de dicho seguimiento y evaluación de la Ventanilla Única: la Comisión de Seguimiento y Evaluación del Convenio Marco. En este caso, veremos cuáles son sus características definitorias: origen, composición, funciones y actividades desarrolladas de manera real en el proceso de implantación de la Ventanilla Única en la Comunidad de Madrid. Una vez aclaradas estas cuestiones, nos introduciremos en el análisis del periodo informal de evaluación y seguimiento de la implantación de la Ventanilla Única en la Comunidad de Madrid viendo cual ha sido el papel desempeñado por la Oficina de Atención al Ciudadano en este proceso.

\subsection{El seguimiento formal de la Ventanilla Única en la Comunidad de Madrid (1998-1999): La Comisión de seguimiento y evaluación del Convenio Marco}

\section{Antecedentes en la creación de una Comisión de Seguimiento y Evaluación del Convenio Marco}

El Acuerdo del Consejo de Ministros del 4 de abril de $1997^{\circ}$ señalaba que la evaluación de las solicitudes de adhesión de las entidades locales al Convenio Marco debía llevarse a cabo por una Comisión mixta ${ }^{10}$ compuesta por representantes de la Administración General del Estado y de la Administración Autonómica. La creación de este órgano no estaba presente en el Acuerdo de 1996 (marco normativo de los Convenios Bilaterales entre la Administración General del Estado y las Entidades Locales) y solo se contemplaba que el Ministerio de Administraciones Públicas debía certificar la idoneidad de las entidades locales para suscribirse al Convenio además de resolver las dudas y controversias derivadas de la interpretación y aplicación de dicho marco normativo.

Sin embargo, debemos resaltar que la existencia de esta Comisión tiene su origen más remoto en una de las pautas contenidas en el articulado de la Ley 30/1992 de Régimen Jurídico de las Administraciones Públicas y del Procedimiento Administrativo Común. En concreto la que hacía referencia a los Convenios de colaboración entre «el Gobierno de la Nación y los órganos de Gobierno de las Comunidades Autónomas» y en este sentido, se expresaba lo siguiente: «los instrumentos de formalización de los Convenios deberán especificar, cuando así proceda: (...) la necesidad o no de establecer un organización para su gestión» ${ }^{11}$.

Tal y como hemos señalado, en el Acuerdo de 1997 se reconocía la existencia de una Comisión cuyo cometido debía ser la evaluación y seguimiento de la implantación de la Ventanilla Única. Sin embargo, no se daba contenido a otra serie de cuestiones básicas como cuál debía ser la composición y las funciones del citado órgano, dejando así que el desarrollo de estos temas fuesen abordados con posterioridad y de manera específica en cada uno de los Convenios Marco suscritos por la Administración General del Estado y cada una de las Administraciones regionales.

Prácticamente un mes después del Acuerdo del Consejo de Ministros, y concretamente el 21 de mayo de 1997 la Comunidad de Madrid firmó un Convenio Marco con la Administración General del Estado. A dicho Convenio podían adherirse aquellas entidades locales pertenecientes al ámbito geográfico de la Comunidad Autónoma de Madrid que así lo solicitasen.

\footnotetext{
${ }^{9}$ Convenio Marco para la implantación de su sistema intercomunicado de registros entre la Administración General del Estado, las Administraciones de las Comunidades Autónomas y las Entidades Locales del ámbito territorial de la Comunidad Autónoma firmante que así lo solicitasen. Publicado en el «Boletín Oficial del Estado» núm. 89, de 14 de abril de 1997.

${ }_{10}$ Apartado Segundo del Acuerdo del Consejo de Ministros de 1.997.

${ }^{11}$ Véase artículo 6 de la Ley de Régimen Jurídico de las Administraciones Públicas y Procedimiento Administrativo Común.
} 
Siguiendo las directrices del Acuerdo del Consejo de Ministros de 1997, en dicho Convenio se creó una Comisión mixta, denominada Comisión de Seguimiento y Evaluación ${ }^{12}$. En términos generales la finalidad de este órgano era: la gestión, vigilancia, control y resolución de los problemas de interpretación que pudieran llegar a plantearse en relación al Convenio subscrito por las entidades firmantes.

\section{Composición de la Comisión de Seguimiento y Evaluación del Convenio Marco}

El Acuerdo del Consejo de Ministros de 1997 solo señalaba que la Comisión mixta debía estar compuesta por representantes de la Administración General del Estado y de la Administración Autonómica. Sin embargo, no concretaba nada más al respecto, dejando de esta manera un vacío sobre cuáles debían ser en concreto los miembros que compondrían la Comisión. Este vacío ha sido resuelto con posterioridad en los Convenios Marcos firmados en cada ámbito territorial.

En el ámbito geográfico de la Comunidad de Madrid, el Convenio Marco firmado por la citada Comunidad Autónoma y la Administración General del Estado transcribe una clara representación mixta en la Comisión de Seguimiento y Evaluación que se traduce en los términos siguientes:

a) En representación de la Administración General del Estado componen la Comisión: el Director General de la Inspección General de Servicios de la Administración Pública quien la copreside; el Subdirector General de Procedimientos y Racionalización de la Gestión; el Subdirector General de Coordinación Informática; el Subdirector General de Cooperación Sectorial con Comunidades Autónomas; y el Jefe del Área Informática de la Inspección General de Servicios de la Administración Pública.

b) En representación de la Administración de la Comunidad de Madrid son miembros de la Comisión: la Viceconsejera de Presidencia quien la copreside; el Director General de Calidad de los Servicios; el Gerente del Organismos Autónomo Informática y Comunicaciones; el Jefe del Servicio de Radiodifusión y Televisión; y el Jefe del Servicio de la Oficina de Información, Iniciativas y Reclamaciones.

Como podemos apreciar en la composición de la Comisión no se contempla la participación de representantes de las entidades locales. Sin embargo, podemos adelantar que en algunas de las sesiones de este órgano se ha contado con la asistencia de representantes de la Federación Madrileña de Municipios.

\section{Las funciones de la Comisión de Evaluación y Seguimiento}

Las funciones de la Comisión tampoco fueron enumeradas en el Acuerdo del Consejo de Ministros de 1997 en el que solo se hizo referencia a la finalidad del órgano en cuestión: la evaluación de las solicitudes de las Entidades Locales que quisieran adherirse al Convenio Marco. De nuevo será en el marco del Convenio Marco subscrito por la Comunidad de Madrid y la Administración General del Estado donde se articulará el ámbito competencial que dará contenido a la citada finalidad ${ }^{13}$.

${ }^{13}$ Cláusula decimotercera del Convenio Marco. 
Las actividades desarrolladas por la Comisión en relación al seguimiento y evaluación de las entidades locales de la Comunidad de Madrid podían agruparse en dos categorías básicas:

a) Un seguimiento «a priori». Este seguimiento sería el realizado por la Comisión antes de la adhesión de las entidades locales al Convenio Marco y su contenido comprendería aquellas actividades relativas a la evaluación de la idoneidad o no de la Entidad Local para poder adherirse al Convenio Marco sobre Ventanilla Única en la Comunidad de Madrid.

En este caso, con el objeto de que la Comisión pudiese corroborar que las entidades locales cumplían los requisitos formales necesarios para agregarse al Convenio, éstas debían remitir a este órgano la siguiente documentación:

- ElProtocolo de Adhesión ${ }^{14}$. El contenido de este documento era a grosso modo una declaración formal de la Entidad Local (a través del órgano a quien le competía la adopción del Acuerdo de adhesión) y de la persona que la representaba, de adherirse al Convenio.

- Certificado del acuerdo del órgano de la Entidad Local por el que se adoptaba la decisión de adherirse al Convenio. La forma mayoritaria de realización del certificado ha sido a través del acuerdo del Pleno del Ayuntamiento, con algunas excepciones en los municipios en que este órgano haya delegado la firma en el Alcalde, en la que junto con el resto de los documentos se debía presentar también un certificado que corroborara la delegación de la citada competencia.

- Un Cuestionario facilitado y elaborado por la Comisión en el que se aportaba la información necesaria sobre los medios y la capacidad de gestión de la Entidad Local que solicitaba subscribirse al Convenio

Además de esta documentación, la Comisión recomendaba también que la oficinas de registro de las Entidades Locales contasen con una serie de requisitos mínimos para poder adherirse al Proyecto Ventanilla Única: ordenador, procesador mínimo 486, impresora, posibilidad de conexión internet, MODEM; así como que la que la apertura de las mismas fuese, como mínimo, de tres horas diarias de lunes a viernes.

La Comisión debía evaluar la documentación citada y en el plazo de quince días tenía que comunicar a la Entidad Local solicitante la aceptación o denegación de dicha adhesión.

b) Un seguimiento «a posteri». Este tipo de seguimiento comenzaría una vez que las entidades locales se hubiesen adherido al Convenio y consiste en la realización de cuantas actuaciones tengan como cometido la gestión, vigilancia y control de la implantación de la Ventanilla Única en la Entidades Locales de la Comunidad de Madrid. Las funciones que debía ejercer la Comisión para el desarrollo de este tipo de seguimiento eran:

- La adopción de cuantas medidas estimase adecuadas para el mejor desarrollo y cumplimiento de los compromisos y obligaciones establecidos en el Convenio Marco y para una adecuada coordinación entre las Administraciones participantes, así como su comunicación a las Administraciones intervinientes.

- La elaboración de un informe anual de seguimiento y evaluación del Convenio marco, y su elevación a las Administraciones intervinientes. Estado.

${ }^{14}$ Este documento venía como anexo en el Convenio Marco firmado por la Comunidad de Madrid y la Administración General del 
- La resolución con carácter ejecutivo de las cuestiones de interpretación y aplicación del Convenio Marco planteadas por las entidades locales adheridas al mismo ${ }^{15}$.

- El examen y resolución de los problemas de interpretación y cumplimiento del Convenio que se suscitasen por la Administración General del Estado o la Administración de la Comunidad de Madrid.

\section{Actividades desarrolladas en la práctica por la Comisión de Seguimiento y Evaluación (1998-1999) ${ }^{16}$}

La Comisión de Seguimiento y Evaluación se constituye el día 17 de septiembre del año 1998. Unos días más tarde (el 23 de septiembre) se celebra su primera sesión de trabajo a la que asisten todos los miembros que la componen, además del Secretario General de la Federación Madrileña de Municipios quien asiste como invitado. El lugar de celebración de esta reunión fue la sede del Gobierno de la Comunidad de Madrid, sitio que a partir de entonces será el lugar habitual de sus sesiones. El objeto de la citada reunión fue: a) El análisis de la evolución de la aplicación del Convenio; b) El estudio de las cuestiones planteadas con motivo de su aplicación y adopción de las decisiones oportunas; c) La ratificación de la adhesión solicitada por algunos ayuntamientos y la firma del correspondiente Protocolo por parte de los dos presidentes de la Comisión.

a) Sobre el primero de los puntos que motivaron esta reunión no tenemos datos que constaten su desarrollo. Por otra parte, debemos destacar que desde la firma del Convenio Marco hasta la fecha de esta primera sesión transcurre aproximadamente un año, y es en el año 1998 (fecha de la reunión) cuando se producen las primeras adhesiones al Convenio. Por todo ello, resultaría lógica, la no disponibilidad de información relativa a un análisis sobre la evolución de la aplicación del citado Convenio.

b) El segundo de los aspectos que debían tratarse en la sesión de la Comisión era el estudio de las cuestiones planteadas en relación con la aplicación al Convenio y la adopción de las decisiones oportunas. En este sentido, las decisiones adoptadas por la Comisión en su primera reunión podrían considerarse como un compendio de instrucciones relativas al trabajo que debían desarrollar algunos de los actores participantes en la gestión del proceso del Proyecto Ventanilla Única en la Comunidad de Madrid. En este sentido, las tareas asignadas a los diferentes actores fueron las siguientes:

- La realización conjunta por parte de la Dirección General de Calidad de los Servicios (DGCS) y la Oficina de Atención al Ciudadano de la Comunidad de Madrid (OAC) de un documento en el que se plasmara las ventajas que podría reportar a los ciudadanos y a los propios ayuntamientos la implantación de la Ventanilla Única.

- La Oficina de Atención al Ciudadano de la Comunidad de Madrid debía crear la siguiente documentación:

- Un listado sobre los ayuntamientos adheridos y ratificados al Convenio.

${ }^{15}$ Esta función podía ser asumida en cualquier momento por las autoridades que suscribían el Convenio en representación del Gobierno de la Nación y de la Comunidad de Madrid, es decir el Presidente de la Comunidad de Madrid y el Ministro del Administraciones Públicas.

${ }_{16}$ El Convenio Marco de implantación de la Ventanilla Única en la Comunidad Autónoma de Madrid fue firmado en el año 1997, sin embargo, no es hasta un año más tarde cuando realmente se pone en práctica. Por ello, hemos tomado como periodo de inicio en nuestro periodo de estudio el año 1998, fecha en la que se presentan las primeras solicitudes de adhesión de las entidades locales al Convenio Marco. 
- Para la futura creación de una Base de Datos de Información de Municipios se le solicitó también: el análisis de los temas de Información General Administrativa de la Comunidad de Madrid que afecta a los Municipios y se incluyen en las Bases de Datos para su difusión por el 012; el análisis de los temas de Información General Administrativa propia de los distintos Municipios, incluidos en las Bases de Datos de la CM y difundidos por el 012; y el control de los documentos procedentes de los Ayuntamientos que han llegado al Registro General de la Comunidad de Madrid en aplicación del Convenio Marco de Ventanilla Única

- Al Organismo Autónomo de Informática y Comunicaciones de la Comunidad de Madrid (ICM) se le asignó la realización de un estudio sobre las posibilidades técnicas de interconexión de las Bases de Datos de la Oficina de Atención al Ciudadano y las Bases de Datos Municipales que existiesen.

Por último, a la Federación Madrileña de Municipios (FMM) se le encargó un análisis de los ayuntamientos que disponían de un servicio propio de Información General Administrativa con un teléfono 010.

c) El último de los aspectos tratados en esta primera sesión fue la ratificación de la adhesión al Convenio de algunos ayuntamientos y la firma del correspondiente Protocolo por los dos copresidentes de la Comisión.

En esta fecha nos encontramos con que 14 ayuntamientos solicitaron su adhesión al Convenio. En el desarrollo de sus competencias, la Comisión debía pronunciarse, una vez revisados los documentos de adhesión presentados por las entidades locales solicitantes (cuestionario de adhesión, Protocolo de adhesión y certificado del Pleno) sobre si reunían los requisitos mínimos fijados para poder adherirse al Convenio. En su primera sesión, la Comisión ratificó la adhesión al Convenio de estas catorce solicitudes, mediante la firma del correspondiente Protocolo ${ }^{17}$.

La segunda vez que se reúne la Comisión de Seguimiento y Evaluación fue el 2 de marzo de 1999. El objetivo principal de esta sesión era que diversos organismos de la Comunidad de Madrid (OAC, DGCS, ICM y FMM) presentaran la información que le fue demandadas según las instrucciones dadas por la propia Comisión en su reunión anterior. Sin embargo, de los actores involucrados en este proceso, sólo la Oficina de Atención al Ciudadano y la Dirección General de Calidad de los Servicios desarrollaron las tareas que le fueron asignadas. Así, la información presentada por la Comunidad de Madrid ante la Comisión fue la siguiente:

a) Un documento informativo sobre las ventajas del acceso al Convenio Marco de Ventanilla Única en la Comunidad de Madrid (CUADRO 5). Este documento fue elaborado de manera conjunta entre la Oficina de Atención al Ciudadano y la Dirección General del Calidad de los Servicios ${ }^{18}$.

Estos datos se insertaron posteriormente en la información dada por la Comunidad de Madrid con respecto al Proyecto de Ventanilla Única en Internet.

\footnotetext{
${ }^{17}$ Debemos recordar que el Protocolo de adhesión era entregado junto con el resto de los documentos presentados por cada Entidad Local en su solicitud de adhesión al Convenio. Sin embargo para que dicha solicitud fuera ratificada era necesario que los copresidentes de la Comisión firmasen el correspondiente Protocolo de adhesión.

${ }^{18} \mathrm{La}$ presentación de este documento estuvo motivada por la propia Comisión en su reunión anterior en la que se acuerda la creación de esta información por los órganos enumerados de la Comunidad de Madrid.
} 


\section{CUADRO 5 \\ Ventajas de la implantación de la Ventanilla Única en la Comunidad de Madrid}

\begin{tabular}{|c|c|c|}
\hline Ventajas para los ciudadanos & Ventajas para las entidades locales & Otras ventajas \\
\hline $\begin{array}{l}\text { - Reducción de los desplazamientos } \\
\text { - Desaparición de aglomeraciones } \\
\text { - Único punto de información y registro } \\
\text { - Inmediatez en la atención e informaci ón } \\
\text { actualizada } \\
\text { - La Administración se aproxima a todos los } \\
\text { vecinos en igualdad de trato }\end{array}$ & $\begin{array}{l}\text { Previsión de la utilización intensiva de las } \\
\text { tecnologías de la información y de la } \\
\text { comunicación } \\
\text { - Cooperación entre los tres niveles } \\
\text { administrativos } \\
\text { - Posibilidad de simplifi car actuaciones } \\
\text { administrativas en que participen los tres } \\
\text { niveles } \\
\text { - No es necesario suscribir múltiples } \\
\text { convenios bilaterales }\end{array}$ & $\begin{array}{l}\text { Papel protagonista de las Entidades Locales } \\
\text { en las relaciones con los ciudadanos } \\
\text { - Acercamiento a los ciudadanos } \\
\text { - Acceso a la informac ión de cualquier } \\
\text { Administración participante y posibilidad de } \\
\text { proyectar su propia información }\end{array}$ \\
\hline
\end{tabular}

Fuente: Elaboración propia a partir de los datos facilitados por la Oficina de Atención al Ciudadano y la D.G. de la Calidad de los Servicios y Atención al Ciudadano de la Comunidad Autónoma de Madrid.

\section{CUADRO 8 \\ Entidades Locales con adbesión ratificada al Convenio Marco basta 1 de marzo de 1999}

\begin{tabular}{|c|c|c|}
\hline Denominación de la EELL & $\begin{array}{c}\mathrm{N}^{\circ} \text { de } \\
\text { habitantes }\end{array}$ & Fecha de adhesión \\
\hline 1. Ayuntamiento de Alcalá de Henares & 188.519 & 21-05-1998 \\
\hline 2. Ayuntamiento de Alcobendas & 98.417 & $20-07-1998$ \\
\hline 3. Ayuntamiento de Aranjuez & 41.897 & 21-05-1998 \\
\hline 4. Ayuntamiento de Arganda del Rey & 36.250 & 18-03-1998 \\
\hline 5. Ayuntamiento de Batres & 1.244 & $23-09-1998$ \\
\hline 6. Ayuntamiento de Buitrago de Lozoya & 1.697 & 20-07-1998 \\
\hline 7. Ayuntamiento de Carabaña & 1.325 & 23-09-1998 \\
\hline 8. Ayuntamiento de Casarrubuelos & 1.460 & $18-03-1998$ \\
\hline 9. Ayuntamiento de Cadalso de los Vidrios & 2.451 & 21-05-1998 \\
\hline 10. Ayuntamiento de Campo Real & 3.310 & $23-09-1998$ \\
\hline 11. Ayuntamiento de Cercedilla & 6.297 & $15-04-1998$ \\
\hline 12. Ayuntamiento de Colmenarejo & 6.235 & \\
\hline 13. Ayuntamiento de Collado Villalba & 50.634 & 21-05-1998 \\
\hline 14. Ayuntamiento de Estremera & 1.135 & 21-05-1998 \\
\hline 15. Ayuntamiento de Fuentidueña de Tajo & 1.517 & 23-09-1998 \\
\hline 16. Ayuntamiento de Guadarrama & 11.957 & 15-04-1998 \\
\hline 17. Ayuntamiento de Meco & 9.217 & 23-09-1998 \\
\hline 18. Ayuntamiento de Navacerrada & 2.231 & 15-04-1998 \\
\hline 19. Ayuntamiento de Navas del Rey & 2.050 & $01-04-1998$ \\
\hline 20. Ayuntamiento de Orusco de Tajuña & 686 & 18-03-1998 \\
\hline 21. Ayuntamiento de Paracuellos del Jarama & 7.088 & 20-07-1998 \\
\hline 22. Ayuntamiento de Pelayos de la Presa & 1.842 & 01-04-1998 \\
\hline 23. Ayuntamiento de Pezuela de las Torres & 503 & 23-09-1998 \\
\hline 24. Ayuntamiento de Quijorna & 1.565 & 01-04-1998 \\
\hline 25. Ayuntamiento de Ribatejada & 400 & $20-07-1998$ \\
\hline 26. Ayuntamiento de Rivas Vaciamadrid & 39.630 & 21-05-1998 \\
\hline 27. Ayuntamiento de Robregordo & 74 & 20-07-1998 \\
\hline 28. Ayuntamiento de San Lorenzo de El Escorial & 14.358 & $15-04-1998$ \\
\hline 29. Ayuntamiento de San Martín de Valdeiglesias & 6.584 & 01-04-1998 \\
\hline 30. Ayuntamiento de Soto del Real & 6.685 & $20-07-1998$ \\
\hline 31. Ayuntamiento de Torrejón de Ardoz & 104.790 & 18-03-1998 \\
\hline 32. Ayuntamiento de Torrejón de Velasco & 2.643 & 18-03-1998 \\
\hline 33. Ayuntamiento de Torrelodones & 17.694 & $15-04-1998$ \\
\hline 34. Ayuntamiento de Villalbilla & 5.854 & 20-07-1998 \\
\hline 35. Ayuntamiento de Villanueva de Perales & 939 & 23-09-1998 \\
\hline
\end{tabular}

Fuente: Elaboración propia a partir de los datos facilitados por la Oficina de Atención al Ciudadano y la D.G. de la Calidad de los Servicios y Atención al Ciudadano de la Comunidad Autónoma de Madrid. 
b) Varios listados sobre entidades locales en los que se especificaba: las entidades locales que hasta el momento habían ratificado su adhesión al Convenio (Cuadro 6); las entidades locales que estaban pendientes de ratificarla (Cuadro 7); y por último, las que habían solicitado su adhesión al Convenio (Cuadro 8).

Como podemos apreciar en el Cuadro 6 aparece el Ayuntamiento de Colmenarejo como entidad local que ratifica su adhesión al Convenio en el año 1998, sin embargo, dicha ratificación nunca llegó a hacerse efectiva a través de su publicación en el BOE y en el BOCAM. Estos hechos provocaron que unos años después, a iniciativa de la Oficina de Atención al Ciudadano quien se puso en contacto con el Ayuntamiento en cuestión, se rescindiera su adhesión al Convenio Marco, siendo hoy uno de los nueve ayuntamientos de la Comunidad de Madrid que no cuentan con Ventanilla Única.

De los datos obtenidos hasta el momento podemos apreciar cómo ha habido un incremento importante en el número de entidades locales, en este caso municipios, que se han adherido al Convenio Marco en un periodo reducido de tiempo (desde septiembre de 1998 hasta marzo de 1999). En este sentido, de los 14 municipios que se habían suscrito al Convenio en 1998 nos encontramos con que en el año 1999 esta cifra aumenta en 21 municipios por lo que en marzo de 1999 ya son 35 los que han ratificado su adhesión al Convenio.

En los cuadros que aparecen a continuación (Cuadro 7 y Cuadro 8) se corrobora la hipótesis anterior ya que en ese mismo año (1999) además de los 35 municipios que ya han ratificado su adhesión al Convenio, nos encontramos con 7 entidades locales pendientes de ratificar su adhesión y con 2 entidades locales que han solicitado sumarse al Convenio.

Esta información nos confirma el interés despertado en las entidades locales por el establecimiento de relaciones de colaboración con el resto de las administraciones participantes en el Convenio Marco (Administración General del Estado y Administración de la Comunidad de Madrid). Relaciones que tienen como objetivo el mejorar y ampliar la prestación de servicios a los ciudadanos.

\section{CUADRO 7 \\ Entidades locales con adbesión pendiente de ratificar basta 1 de marzo de 1999}

\begin{tabular}{|l|c|}
\hline \multicolumn{1}{|c|}{ Denominación de la EELL } & $\begin{array}{c}\mathbf{N}^{{ }^{\circ}} \text { de } \\
\text { habitantes }\end{array}$ \\
\hline 1. Ayuntamiento de Grinón & 6.594 \\
\hline 2. Ayuntamiento de Navalcarnero & 15.768 \\
\hline 3. Ayuntamiento de Valdemorillo & 7.860 \\
\hline 4. Ayuntamiento de Valverde de Alcalá & 332 \\
\hline 5. Ayuntamiento de Villa del Prado & 4.784 \\
\hline 6. Ayuntamiento de Villamanta & 1.785 \\
\hline 7. Ayuntamiento de Villamantilla & 416 \\
\hline
\end{tabular}

Fuente: Elaboración propia a partir de los datos facilitados por la Oficina de Atención al Ciudadano y la D.G. de la Calidad de los Servicios y Atención al Ciudadano de la Comunidad Autónoma de Madrid.

\section{CUADRO 8}

\section{Entidades locales que ban solicitado la adbesión al Convenio Marco con fecha de 1 de marzo de 1999}

\begin{tabular}{|l|c|}
\hline \multicolumn{1}{|c|}{ Denominación de la EELL } & $\begin{array}{c}\mathbf{N}^{{ }^{\circ}} \text { de } \\
\text { habitantes }\end{array}$ \\
\hline 1. Ayuntamiento de Tres Cantos & 38.804 \\
\hline 2. Ayuntamiento de Villanueva de la Cañada & 12.525 \\
\hline
\end{tabular}

Fuente: Elaboración propia a partir de los datos facilitados por la Oficina de Atención al Ciudadano y la D.G. de la Calidad de los Servicios y Atención al Ciudadano de la Comunidad Autónoma de Madrid. 
c) Los Datos numéricos de los documentos llegados al Registro General de la Comunidad de Madrid, procedentes de los ayuntamientos, en aplicación del Convenio Marco de Ventanilla Única.

El Cuadro 9 representa a aquellas entidades locales que han informado a la Oficina de Atención al Ciudadano sobre los documentos registrados en sus oficinas de Ventanilla Única diferenciándolos por tipo Administración a la que iban destinados. Como podemos apreciar el número total de documentos registrados en las cinco entidades locales ha sido 400, y la mayor parte de ellos iban dirigidos a la Administración General del Estado

\section{CUADRO 9}

Datos numéricos de los documentales llegados al registro general de la CAM procedentes de las Entidades Locales en aplciación al Convenio Marco de ventanilla única (27 de abril de 1998 a 22 de febrero de 1999)

\begin{tabular}{|c|c|c|c|}
\hline Entidad Local & $\begin{array}{c}\mathbf{N}^{\mathbf{o}} \text { de } \\
\text { documentos } \\
\text { recibidos }\end{array}$ & $\begin{array}{c}\text { Con destino a la } \\
\text { Comunidad de } \\
\text { Madrid }\end{array}$ & $\begin{array}{c}\text { Con destino a } \\
\text { algún } \\
\text { Ministerio }\end{array}$ \\
\hline Ayto de Pezuela de las Torres & 1 & 1 & 0 \\
\hline Ayto de Cadalso de los Vidrios & 1 & 1 & 0 \\
\hline Ayto de Arganda del Rey & 22 & 22 & 0 \\
\hline Ayto de Alcobendas & 60 & 28 & 32 \\
\hline Ayto de San Martín de Valdeiglesias & 316 & 63 & 253 \\
\hline Total & $\mathbf{4 0 0}$ & $\mathbf{1 1 5}$ & $\mathbf{2 8 5}$ \\
\hline
\end{tabular}

Fuente: Elaboración propia a partir de los datos facilitados por la Oficina de Atención al Ciudadano y la Dirección General de Calidad de los Servicios y Atención al Ciudadano de la Comunidad Autónoma de Madrid.

d) Relación de temas de Información General Administrativa de la Comunidad de Madrid que afecta a los ayuntamientos o que directamente ha sido facilitada por los entes locales con el deseo de su difusión por el 012 y que se contiene en las Bases de Datos de la Oficina de Atención al Ciudadano.

En el Cuadro 10 podemos ver cómo la información recopilada por la Oficina de Atención al Ciudadano y facilitada por las administraciones en cuestión, es bastante escasa. Éste hecho nos llevaría a pensar que el «intercambio de información» entre los tres niveles administrativos (compromiso reflejado en el Convenio Marco) se cumple de manera bastante parcial.

\subsection{El seguimiento informal de la Ventanilla Única en la Comunidad de Madrid (1999-2005)}

El periodo formal de funcionamiento de la Comisión finaliza tras la celebración de la segunda de sus sesiones de trabajo. A partir de entonces no se ha llevado a cabo por este órgano ninguna otra reunión. Esto ha provocado que las funciones de la Comisión hayan sido asumidas de manera informal por otros actores u órganos participantes en el proceso, entre los que podemos destacar la Oficina de Atención al Ciudadano de la Comunidad de Madrid.

Desde el año 1999, el procedimiento de adhesión informal al Convenio Marco sobre Ventanilla Única ha consistido en lo siguiente: a) los municipios remitían su solicitud de adhesión a la Oficina de Atención al 
Ciudadano de la Comunidad de Madrid; b) la Oficina revisaba que el expediente presentado cumplía los requisitos y hacía tres copias del citado expediente (una para la Comunidad de Madrid, otra para la Administración General del Estado y otra para la entidad local); c) y por último se enviaba el expediente al Ministerio de Administraciones Públicas. De esta manera, la Oficina de Atención al Ciudadano se convertía en el órgano que llevaba a cabo la evaluación de las solicitudes, asumiendo el papel y las competencias de la Comisión de Seguimiento y Evaluación en el proceso de seguimiento «a priori».

\section{CUADRO 10}

Información recopilada y elaborada por la oficia de atención al ciudadano de la Comunidad de Madrid y la facilitada por las entidades locales (1 de marzo de 1999)

\begin{tabular}{|c|c|}
\hline $\begin{array}{l}\text { INFORMACIÓN } \\
\text { RECOPILADA Y } \\
\text { ELABORADA POR LA } \\
\text { OFICINA DE ATENCIÓN AL } \\
\text { CIUDADANO DE LA } \\
\text { COMUNIDAD DE MADRID }\end{array}$ & 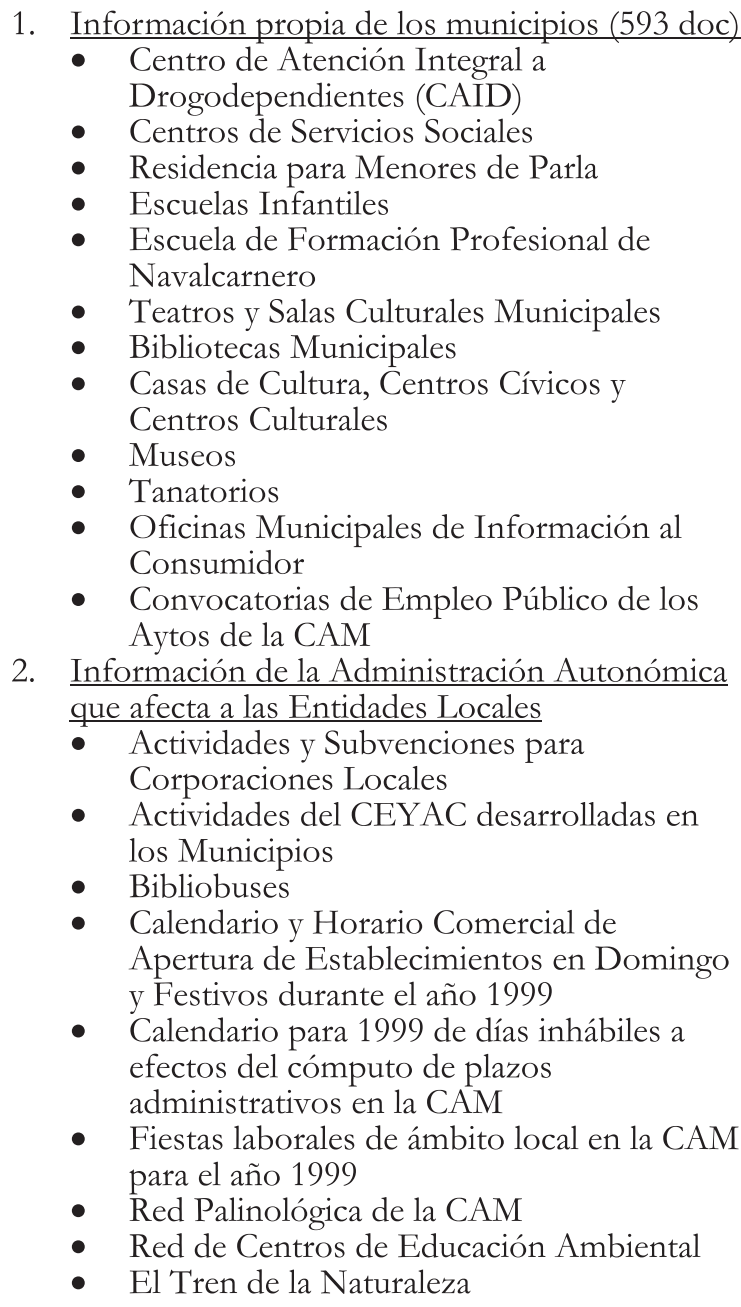 \\
\hline $\begin{array}{l}\text { INFORMACIÓN } \\
\text { FACILITADA POR LAS } \\
\text { ENTIDADES LOCALES }\end{array}$ & $\begin{array}{l}\text { - Programa del Teatro Bulevar de } \\
\text { Torrelodones } \\
\text { - Programación Cultural de Arganda del Rey } \\
\text { - Programación Cultural de San Fernando de } \\
\text { Henares }\end{array}$ \\
\hline
\end{tabular}


Si analizamos los distintos documentos que las entidades locales debían presentar a la Oficina de Atención al Ciudadano, podemos señalar que:

a) El cuestionario de adhesión era un escrito que aportaba información sobre los datos generales de la entidad local que solicitaba adherirse al Convenio, sus medios y su capacidad de gestión. Los criterios aparecidos en este documento no se han modificado ni revisado desde su elaboración. Además tampoco se han evaluado con detenimiento los aspectos que hacen referencia a los recursos (humanos, materiales y tecnológicos) con los que cuenta la entidad local para implantar el modelo de Ventanilla Única.

El único interés que ha despertado hasta el momento la evaluación del cuestionario ha sido el poder obtener información sobre el número de registros de los ayuntamientos, y sobre los días laborables del municipio, así como de los días hábiles e inhábiles y de los horarios de apertura y cierre del registro.

b) Además del cuestionario, las entidades locales debían presentar, en este caso, ante la Oficina de Atención al Ciudadano: el Protocolo de Adhesión y el certificado del acuerdo del órgano de la entidad local por el que se adopta la decisión de adherirse al Convenio ${ }^{20}$.

La ratificación del Convenio se hacía mediante la firma del Protocolo de adhesión por parte de los Presidentes de la Comisión. Como ya hemos comentado con anterioridad este órgano no se ha reunido desde el año 1999 por lo que la mayor parte de las firmas realizadas a partir de esta fecha se han llevado a cabo mediante actos públicos a los que han acudido representantes políticos de los municipios y de la Comunidad Autónoma de Madrid, junto con un representante de la Federación Madrileña de Municipios. En algunas ocasiones en este tipo de actos informales de adhesión se entregaba una placa conmemorativa a cada entidad local que se adhería al Convenio Marco.

Con carácter previo al citado acto público de adhesión, la Oficina de Atención al Ciudadano comunicaba (mediante llamadas telefónicas) la decisión adoptada a los solicitantes. Desde el año 1998 hasta la actualidad no se ha producido ninguna denegación a las solicitudes presentadas por las entidades locales. Esto ha supuesto un incremento importante en el número de entidades locales que cuentan con Ventanilla Única en el seno de la Comunidad de Madrid.

Además de las actividades derivadas de la evaluación de las solicitudes de adhesión al Convenio Marco, la Oficina de Atención al Ciudadano ha realizado otras tareas de seguimiento «a posteriori» de la implantación de Ventanilla Única en la Comunidad de Madrid. Una de estas tareas ha consistido en la realización de un informe anual, cuyo contenido ha versado sobre el número de entidades locales que se han ido adhiriendo al Convenio Marco. Dicho listado comprende no solo la fecha de adhesión al Convenio sino también la de publicación de la citada resolución tanto en el BOE como el BOCAM.

Esta información ha servido a la Oficina de Atención al Ciudadano para establecer un control o seguimiento sobre el estado de la implantación de la Ventanilla Única en las entidades locales. No debemos olvidar que aunque la Entidad Local se haya adscrito al Convenio Marco este solo se activa tras su publicación en el BOE y BOCAM. En este sentido, la labor desempeñada por la Oficina de Atención al Ciudadano ha consistido en: identificar a las entidades locales que constataban retrasos en la puesta en práctica del modelo Ventanilla Única y ponerse en contacto con ellas (mediante llamadas telefónicas) con el objeto de subsanar el problema y activar la implantación de la Ventanilla Unica en la entidad local en cuestión.

${ }^{20}$ Sobre el certificado del acuerdo del órgano de la Entidad Local por el que se adopta la decisión de adherirse al Convenio véase el apartado 3.1.3 sobre: «Las funciones de la Comisión de Seguimiento y Evaluación». 
El Cuadro 11 nos ofrece un listado de todas aquellas entidades locales que han dejado transcurrir un periodo de tiempo hasta que realmente publican su adhesión al Convenio, y por consiguiente ponen en marcha el modelo Ventanilla Única. Como podemos apreciar nos encontramos con varios casos extremos entre aquellos municipios que se adhirieron al Convenio en el año 1998: por un lado, el Ayuntamiento de Casarrubuelos deja transcurrir siete años hasta que publica dicha resolución; y por otro lado, los Ayuntamientos de Carabaña, Alcalá de Henares y Torrejón de Ardoz que no llegan a publicar su adhesión hasta el año 2003, pasando así cinco años desde la fecha de su adhesión al Convenio.

\section{CUADRO 11}

\section{Datos sobre las EELL de la Comunidad de Madrid que se adbieren al Convenio Marco de Ventanilla Única con una fecha de publicación posterior a la adbesión}

\begin{tabular}{|c|c|c|c|}
\hline Denominación de la EELL & $\mathbf{N}^{\circ}$ de habitantes & $\begin{array}{l}\text { Fecha de } \\
\text { adhesión }\end{array}$ & $\begin{array}{c}\text { Fecha de } \\
\text { publicación }\end{array}$ \\
\hline 1. Ayto de Batres & 1.244 & 23-09-1998 & 27-11-2001 \\
\hline 2. Ayto de Buitrago de Lozoya & 1.697 & $20-07-1998$ & $15-12-2000$ \\
\hline 3. Ayto de Cadalso de los Vidrios & 2.451 & 21-05-1998 & 09-04-1999 \\
\hline 4. Ayto de Campo Real & 3.310 & 23-09-1998 & 24-03-1999 \\
\hline 5. Ayto de Carabaña & 1.325 & 23-09-1998 & $08-05-2003$ \\
\hline 6. Ayto de Casarrubuelos & 1.460 & 18-03-1998 & $25-09-2005$ \\
\hline 7. Ayto de Estremera & 1.135 & $21-05-1998$ & 09-04-1999 \\
\hline 8. Ayto de Navacerrada & 2.231 & 15-04-1998 & $20-12-2000$ \\
\hline 9. Ayto de Navas del Rey & 2.050 & 01-04-1998 & 08-04-1999 \\
\hline 10.Ayto de Orusco de Tajuña & 686 & 18-03-1998 & 31-03-1999 \\
\hline 11. Ayto de Pelayos de la Presa & 1.842 & 01-04-1998 & 29-04-1999 \\
\hline 12. Ayto de Quijorna & 1.565 & 01-04-1998 & 18-03-1999 \\
\hline 13. Ayto de Ribatejada & 400 & $20-07-1998$ & 23-04-1999 \\
\hline 14. Ayto de Robregordo & 74 & $20-07-1998$ & 23-04-1999 \\
\hline 15. Ayto de Villanueva de Perales & 939 & 23-09-1998 & $27-11-2001$ \\
\hline 16. Ayto de Villa del Prado & 4.784 & 23-09-1998 & $22-10-2001$ \\
\hline 17. Ayto de Cercedilla & 6.297 & $15-04-1998$ & 31-03-1999 \\
\hline 18. Ayto de Griñón & 6.594 & 23-09-1998 & $20-10-2000$ \\
\hline 19. Ayto de Meco & 9.217 & 23-09-1998 & 13-05-1999 \\
\hline 20. Ayto de Paracuellos del Jarama & 7.088 & $20-07-1998$ & 24-04-1999 \\
\hline 21. Ayto de Soto del Real & 6.685 & $20-07-1998$ & $18-09-2000$ \\
\hline 22. Ayto de Torrelodones & 17.964 & 15-04-1998 & $16-11-2001$ \\
\hline 23.Ayto de Villalbilla & 5.854 & $20-07-1998$ & 24-03-1999 \\
\hline 24. Ayto de Villanueva de la Cañada & 12.525 & 24-03-1998 & 07-05-1999 \\
\hline 25. Ayto de Aranjuez & 41.897 & 21-05-1998 & 30-03-1999 \\
\hline 26. Ayto de Rivas-Vaciamadrid & 39.630 & 21-05-1998 & 19-04-1999 \\
\hline 27. Ayto de Tres Cantos & 38.804 & 25-03-1998 & 13-05-1999 \\
\hline 28. Ayto de Collado Villalba & 50.634 & 21-05-1998 & 04-01-1999 \\
\hline 29. Ayto de Alcalá de Henares & 188.315 & 21-05-1998 & 08-05-2003 \\
\hline 30. Ayto de Torrejón de Ardoz & 104.790 & 18-03-1998 & 08-05-2003 \\
\hline 31.Ayto de Álamo, El & 5.784 & $13-01-2000$ & 19-04-2001 \\
\hline 32. Ayto de Fuente el Saz de Jarama & 5.260 & $14-04-2000$ & $14-02-2001$ \\
\hline 33. Ayto de Navalcarnero & 15.768 & $13-01-2000$ & 07-05-2002 \\
\hline 34. Ayto de San Martín de la Vega & 13.446 & $13-11-2000$ & $22-02-2001$ \\
\hline 35. Ayto de Valdemorillo & 7.860 & $13-01-2000$ & $17-01-2001$ \\
\hline 36. Ayto de Getafe & 156.315 & $14-12-2001$ & $11-02-2002$ \\
\hline 37. Ayto de Leganés & 176.900 & $14-12-2001$ & $11-02-2002$ \\
\hline 38. Ayto de Móstoles & 201.789 & $14-12-2001$ & $11-02-2002$ \\
\hline 39. Ayto de Serranillos del Valle & 2.206 & $14-12-2001$ & $11-02-2002$ \\
\hline 40. Ayto de Moraleja de Enmedio & 3.629 & $14-12-2001$ & $11-02-2002$ \\
\hline 41. Ayto de Pedrezuela & 2.033 & 14-12-2001 & 05-03-2002 \\
\hline 42. Ayto de Arroyomolinos & 6.116 & $14-12-2001$ & $11-02-2002$ \\
\hline 43. Ayto de Ciempozuelos & 16.058 & $14-12-2001$ & $11-02-2002$ \\
\hline 44. Ayto de Colmenar de Oreja & 6.257 & $27-06-2001$ & 05-03-2002 \\
\hline 45. Ayto de Moraleja de Enmedio & 3.629 & $14-12-2001$ & $11-02-2002$ \\
\hline 46 Ayto de Pedrezuela & 2.033 & $14-12-2001$ & 05-03-2002 \\
\hline
\end{tabular}




\section{Conclusiones}

La información aportada sobre la implantación y el seguimiento de la Ventanilla Única en los municipios de la Comunidad de Madrid permite extraer algunas conclusiones generales que sumariamente pasamos a exponer:

- Desde su inicio el Proyecto Ventanilla Única en el ámbito geográfico de la Comunidad de Madrid se enmarca dentro del conjunto de medidas que componen la política de calidad puesta en práctica por dicha Comunidad Autónoma.

De esta situación, podríamos deducir que aparentemente la Ventanilla Única no debería ser una medida independiente o aislada de los programas que pretenden modificar las estructuras y la cultura organizativa dentro de las Administraciones públicas, en concreto, de la Administración regional y por influencia de ésta, de las Administraciones locales. Sin embargo, la voluntad inicial y la durabilidad del Proyecto no se plantea en los Planes de Simplificación Administrativa que van a marcar las políticas innovación y modernización administrativa en la Comunidad de Madrid, lo que dificulta la credibilidad de esta actuación.

- En lo que se refiere a la modernización que presupone la Ventanilla Única en el marco de las relaciones interadministrativas, debemos resaltar que para el éxito de este tipo de Proyectos, las relaciones entre las administraciones implicadas deberían partir de unos objetivos y capacidad común. A la luz de los resultados, no podemos afirmar que tal circunstancia haya sido tenida en cuenta a lo largo de la implantación del Proyecto Ventanilla Única en el seno de la Comunidad de Madrid.

- Aunque, por un lado, la mayor parte de las entidades locales de la Comunidad de Madrid (en este caso, municipios) hayan aceptado implantar este modelo de gestión, por otro lado se han encontrado con una serie de inconvenientes que tal vez, deberían ser revisados en un futuro para agilizar el desarrollo de esta herramienta. Por ejemplo:

- No se ha contemplado, en ningún momento, una inyección de recursos humanos y económicos que de alguna manera ayudarían a mejorar la puesta en práctica de este modelo. Sobre todo, si tenemos en cuenta que los municipios mediante la apertura de la Ventanilla Única consiguen una ampliación de los servicios que prestan a los ciudadanos contando con los mismos medios de los que ya disponían.

- La no transferencia de recursos no se corresponde con el nivel de responsabilidad que asumen las entidades locales. En colación con este punto se derivan una serie de problemas que normalmente suelen llevar en solitario las entidades locales: por un lado se convierten en «puertas de entrada» de las quejas, sugerencias y reclamaciones destinadas a las otras administraciones (central y regional); y por otro lado, esta responsabilidad no se ve recompensada con un esfuerzo de la autonomía local, al no reconocérseles una competencia que en realidad asumen, siendo su papel el de meras ejecutoras.

- En relación con la aplicación de las Tecnologías de la Información y Comunicación a la Ventanilla Única, también nos hemos encontrado con una serie de dificultades todavía no resueltas. Por ejemplo: la red informática utilizada hasta el momento ha hecho que la Ventanilla Única se convierta en un simple registro de documentos, sin dar paso a la Teleadministración que permitiría la resolución inmediata de los trámites administrativos.

- La puesta en práctica de la Ventanilla Única en la Comunidad de Madrid no ha ido acompañada de una evaluación en profundidad de las solicitudes de adhesión presentadas por las entidades locales y de un seguimiento que nos pueda aportar datos sobre cuál ha sido el funcionamiento real de esta herramienta, y de sus efectos en la eficacia y eficiencia de la prestación de los servicios públicos a los ciudadanos. La inexistencia de este seguimiento ha supuesto la no revisión y rediseño del modelo de Ventanilla Única a pesar de que han transcurrido aproximadamente unos siete años desde las primeras adhesiones a este Proyecto en la Comunidad de Madrid. 
- Sobre el cómo se ha realizado, en la práctica, el seguimiento y la evaluación de la Ventanilla Única en la Comunidad de Madrid, podemos señalar lo siguiente:

- A pesar de que en el Convenio Marco firmado por la Comunidad de Madrid y la Administración General del Estado se creaba un órgano (la Comisión de Seguimiento y Evaluación) cuya finalidad era asumir las funciones derivadas del seguimiento y la evaluación del Proyecto Ventanilla Única en las entidades locales de la Comunidad de Madrid, este órgano no ha llevado a cabo la mayor parte de las competencias encomendadas, de hecho solamente se ha reunido en dos ocasiones entre los años 1998 y 1999. Por ello, y de manera informal, sus funciones han sido desarrolladas, por otra serie de órganos de la Comunidad de Madrid, y principalmente por la Oficina de Atención al Ciudadano.

- En la práctica y de manera general, la evaluación y seguimiento de la implantación de la Ventanilla Única en la Comunidad de Madrid ha consistido en:

- Un seguimiento «a priori» (antes de la adhesión de la EELL al Convenio) sobre la idoneidad de la entidad local para poder adherirse al Convenio sobre Ventanilla Única. Esta evaluación ha consistido en una revisión cuantitativa de los documentos aportados por las entidades locales sin entrar en un estudio en profundidad sobre si se cumplían o no los requisitos mínimos exigidos para adherirse al Convenio. Requisitos que por otra parte venían reflejados en el cuestionario de solicitud adhesión aportado por cada una de las entidades locales solicitantes.

- En un seguimiento «a posteri» (después de que la EELL se hubiera adherido al Convenio mediante la firma del correspondiente Protocolo de adhesión). Seguimiento que se ha llevado a cabo por la Oficina de Atención al Ciudadano y que ha consistido en la realización de dos actividades básicas: a) la elaboración de un informe anual sobre el seguimiento y evaluación del Convenio Marco cuyo contenido se ha centrado en contabilizar a aquellas entidades locales que se habían sumado al Convenio por fechas de adhesión y publicación (seguimiento cuantitativo); b) y el control del estado de implantación de la Ventanilla Única en las entidades locales: ver si tras la firma del Protocolo se había activado la Ventanilla Única mediante la publicación de la resolución en el Boletín Oficial correspondiente.

- A pesar de los datos aportados, podemos concluir señalando que la Ventanilla Única en la Comunidad de Madrid es un instrumento de gestión que se ha implantado con éxito desde el punto de vista de la participación despertada en las entidades locales, ya que de los 178 municipios existentes en el ámbito geográfico de la Comunidad de Madrid, podemos decir que casi todos ellos (169 municipios, el 95\%) cuentan ya con Ventanilla Única (Véase Cuadro 12)

CUADRO 12

Análisis comparativo entre el número de EELL que se ban adberido al Convenio Marco de Ventanilla Única de la Comunidad de Madrid y las que no

\begin{tabular}{|c|c|c|}
\hline EELL & $\mathbf{N}^{\mathbf{0}}$ de EELL & $\mathbf{\%}$ \\
\hline EELL adheridas & 169 & $95 \%$ \\
\hline EELL no adheridas & $9^{120}$ & $5 \%$ \\
\hline Total & $\mathbf{1 7 8}$ & $\mathbf{1 0 0 \%}$ \\
\hline
\end{tabular}

Fuente: Elaboración propia a partir de los datos facilitados por la Dirección General de la Calidad de los Servicios y Atención al Ciudadano de la Comunidad Autónoma de Madrid.

${ }^{20}$ Los municipios de la Comunidad de Madrid que no cuentan con Ventanilla Única son: Ambite, Colmenarejo, Fuenlabrada, Gargantilla de Lozoya, Madrid, Navarredonda, Somosierra, Velilla de San Antonio y Venturada. 
- Para finalizar, simplemente reseñar que en julio de este año se han aprobado medidas normativas ${ }^{21}$ que abordan nuevas directrices y perspectivas de reflexión con respecto al tema que estamos abordando. Este novedoso marco de referencia, indudablemente afectará, en un futuro, a la reformulación, el rediseño y el desarrollo del Proyecto de Ventanilla Única.

\section{REFERENCIAS BIBLIOGRÁFICAS}

Barcelay, M. (2000), The New Public Management. Berkeley: University of California Press.

Beltrán, M. (1996), «De la reforma de la Administración al control de calidad de los servicios públicos», Gestión y Análisis de Politicas Públicas 5-6.

Crespo, J. y Pastor, G. (2002), Administraciones Públicas Españolas. Madrid: McGraw-Hill.

Dirección General de la Calidad de los Servicios y Atención al Ciudadano (2001), Gestiona tú mismo. Plan Estratégico de Simplificación de la Gestión Administrativa (2001-2003). Madrid: Comunidad de Madrid.

Consejería de Presidencia, Dirección General de la Calidad de los Servicios y Atención al Ciudadano (2005), 2. ${ }^{a}$ Fase del Plan Estratégico de Simplificación de la Gestión Administrativa 2005-2007. Madrid: Comunidad de Madrid.

Dunleavy, P., Hood, CH., (1995), «De la administración pública tradicional a la nueva gestión pública. Ensayo sobre la experiencia modernizadora de diversos países desarrollados», Gestión y Análisis de Politicas Públicas 3.

Dunsire, A., Hood, CH., (1989), Cutback management in public bureaucracies. Popular theories and observed outcomes in Whitehall. Cambridge: Cambridge University Press.

Elena, A. (1999), «El Proyecto Ventanilla Única», Revista Iberoamericana de Administración Pública 3.

Embid, A. (1996), El ciudadano y la Administración. Madrid: MAP.

KPMG y Comunidad de Madrid (1997), Guía para la implantación de la Ventanilla Única en la Comunidad de Madrid.

López, J. y Gadea, A. (2001), Una nueva Administración Pública. Estrategias y métodos para mejorar la calidad y la eficiencia del e-Gobierno. Oñate: IVAP.

MAP (2000), Libro Blanco para la Mejora de los Servicios Públicos. Una Nueva Administración al servicio de los ciudadanos. Madrid: MAP.

McLaughlin, K., Osborne, S.P. y Ferlie, E., eds. (2002), New Public Management. Current trends and future prospects. London: Routledge.

Mesa, L. de (2000), «La mejora de la gestión y la calidad de los servicios públicos administrativos en España: un largo camino por recorren», Análisis Local 29.

Minogue, M. y Polidano, C., eds. (1998), Beyond the New Public Management. Changing Ideas and practices in Governance.

Moore, M.H. (1998), Gestión estratégica y creación de valor en el sector público, Barcelona: Paidós.

OCDE (1997), Un Gobierno Alerta. Iniciativas de Servicios de Calidad en la Administración. México.

Olías de Lima, B. (2001), La Nueva Gestión Pública. Madrid: Prentice-Hall.

Ormond, D. y Löffler, E. (1999), «Nueva Gerencia Pública: ¿qué tomar y qué dejar?», Reforma y Democracia 13.

Pastor, G. (2001), Información y comunicación. La Nueva Gestión Pública. Madrid. Prentice Hall.

${ }^{21}$ Nos estamos refiriendo al Acuerdo del Consejo de Ministros de 15 de julio de 2005 para la implantación de una Red de Oficinas Integradas de Atención al Ciudadano en colaboración con las Comunidades Autónomas y las Entidades que integran la Administración Local (BOE n.. 184, 3 de agosto de 2005). 
Pastor, G. y García, M.J. (2005), «Aproximación al Proyecto Ventanilla Única como herramienta de gestión en las Administraciones Públicas», Revista CUNAL, Abril.

Peters, B.G. y Pierre, J. (2000), «Citizens versus the New Public Management. The Problem of Mutual Empowerment», Administration \& Society 1-32.

Pollit, Ch. (2000), «Is the Emperator in his Underwear? An analysis of the impacts of public management reform», Public Management 2-2.

Prats, J. (1996), «Derecho y Management en las Administraciones Públicas». Lecturas de Gestión Pública. Madrid: MAP.

Villacé, C. y Beitia, R. (1999), «La Ventanilla Única. La experiencia de la Junta de Castilla y León», El Consultor de los Ayuntamientos 1. Madrid.

Wright, V. (1997), «Redefiniendo el Estado: las implicaciones para la Administración Pública», Gestión y Análisis de Politicas Públicas $7-8$. 